\title{
AN UNILATERAL VARIANT FORMATION OF MEDIAN NERVE BY THREE ROOTS: TWIN LATERAL ROOTS AND SINGLE MEDIAL ROOT
}

Sreekanth. T, Mohd. Siddeque Ahmed Khan, Mahesh Vemavarapu, Nitya. J.

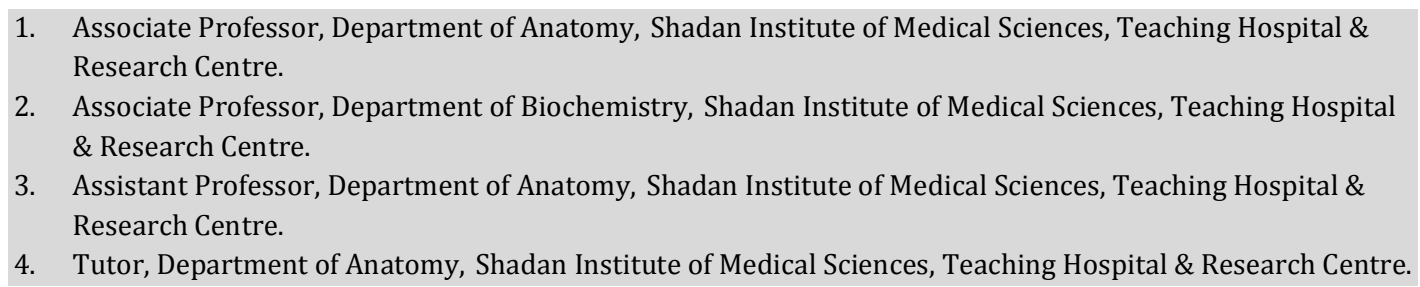

\section{CORRESPONDING AUTHOR}

Dr. Sreekanth. T,

Shadan Institute of Medical Sciences,

Teaching Hospital \& Research Centre,

E-mail: anatomysreekanth18@yahoo.com

Ph: $00919848826008,04023345429$.

\begin{abstract}
The present case report describes one of the rare unilateral variations in the formation of median nerve by the union of three roots, twin (two) roots given off by the lateral cord and one root given off by the medial cord encountered in the right upper arm of an adult male cadaver during the pro-section hours. From the lateral cord which was seen lateral to the third part of axillary artery the musculocutaneous nerve and the twin lateral roots were seen arising very close to each other. The musculocutaneous nerve coursed laterally to innervate the coracobrachialis muscle. The origin of twin lateral roots was just medial to the origin of musculocutaneous nerve. The first lateral root which emerged proximal to the shoulder and united with the medial root and formed the median nerve was labeled as LR - 1, the second lateral root which fused with the already formed median nerve was labeled as LR - 2, In fact the second lateral root LR - 2, and the musculocutaneous nerve had a common point of origin seen as small bulge. The second lateral root LR -2 , was slightly thicker in its diameter and longer in course than the first root LR - 1 and it maintained its individual identity for about $3.5 \mathrm{~cm}$ before merging with the median nerve lying antero-lateral to it. The median nerve was seen forming anterior to the third part of axillary artery which continued as brachial artery. The knowledge of the formation, course and distribution with all the possible variations is an essential prerequisite for traumatologists, neurologists, surgeons performing shoulder arthroscopy by anterior gleno-humeral portal and shoulder reconstructive surgeries, neuro-surgeons performing neurotization of median nerve.
\end{abstract}

KEYWORDS: [Median nerve] [lateral cord] [Medial cord] [Root] [Axillary artery].

INTRODUCTION: The Median nerve is normally formed by the union of two roots: lateral root of median nerve coming from the lateral cord (C5, C6, C7) of brachial plexus and medial root coming from the medial cord $(\mathrm{C} 8, \mathrm{~T} 1)$ of brachial plexus. The two roots embrace the third part of the Axillary artery, uniting anterior or lateral to it. Some fibers from C7 often leave the lateral root in the lower part of the axilla passing distomedially posterior to the medial root, usually anterior to axillary artery, to join the ulnar nerve. In the middle of the arm median nerve crosses 
from lateral to medial side in front of the brachial artery and accompanies it lying medially .In the cubital fossa the nerve passes beneath the bicipital aponeurosis and lies above brachialis . By passing in between the superficial and deep heads of pronator teres it enters the flexor compartment of fore arm where it is coursing in between the flexor diigitorum superficialis and flexor digitorum profundus. The median nerve is plastered to the under surface of the flexor digitorum superficialis. About $5 \mathrm{~cm}$ above the flexor digitorum superficialis it emerges from the under cover of the lateral border of the flexor digitorum superficialis. It is identified due to its dull appearance and its accompanying artery unlike the tendon of Palmaris longus which is glistening and avascular. It enters the carpal tunnel deep to the flexor retinaculum and beyond its distal border divides into lateral and medial branches. The lateral branch supplies the three thenar muscles and subdivides into proper palmar digital nerves supplying the lateral 1 and $1 / 2$ fingers and the $1^{\text {st }}$ lumbrical. The medial branch subdivides into two lateral and medial common palmar digital branches the lateral branch supplies the second lumbrical. It provides cutaneous branches to the palmar aspect of the thumb, index and middle fingers and the radial half of the ring finger.

MATERIAL AND METHODS: The present variation was observed during routine prosection hours for the first year M.B.B.S students, in an embalmed elderly male cadaver in the Department of Anatomy at Shadan Institute of Medical Sciences Teaching Hospital \& Research Centre, Peerancheru, Hyderabad, Andhra Pradesh.

OBSERVATION: During dissection of an elderly male cadaver, the right upper arm showed a variant formation of median nerve by three roots, twin roots were given off by the lateral cord, and single root was given off by the medial cord. The lateral cord was seen lying lateral to the third part of the axillary artery. The lateral pectoral nerve supplying the pectoralis major was given high above in the axilla. The origins of the twin lateral roots were just medial to the origin of musculocutaneous nerve. The first lateral root that began proximal to the shoulder and united with the medial root and formed the median nerve was labeled as LR -1 , the second lateral root which fused with the already formed median nerve was labeled as LR -2 . The medial root was labeled as MR. In fact the second lateral root LR - 2, and the musculocutaneous nerve had a common point of origin which was seen as a small bulge indicated in the figure by two arrows. The musculocutaneous nerve coursed laterally to supply the coracobrachialis muscle. The first lateral root is labeled as LR -1 , which is indicated by a single arrow coursed medially towards the medial root of median nerve and joined with it in front of the third part of axillary artery. The second lateral root [ LR - 2 ]was seen originating just lateral to it slightly thicker in diameter and longer in course than the first lateral root[ LR 1]. It also coursed medially to join the already formed median nerve anterior to the axillary artery. The second lateral root[ LR - 2] showed a kink / pinched appearance at the commencement of contact with the median nerve, [indicated by star placed above it] and was seen lying antero-laterally on median nerve. It remained distinct and its individual identity was appreciable for about $3.5 \mathrm{~cm}$ (indicated by several arrows) before it merged with the median nerve. Its further course through the lower arm, forearm and hand was in accordance with the description given in any of the standard anatomy textbooks. However the left arm showed no such variation.

DISCUSSION: This type of variation described in the present case report in which there are three roots contributing to the formation of the median nerve can be explained on the basis of 
embryogenic development. In the seventh week of Intra-uterine life the musculature of the limb is initially indicated as condensation of mesenchyme near the base of limb bud. With further elongation of the limb buds the musculature splits into flexor and extensor compartments. The upper limb buds lie opposite the lower five cervical and upper two thoracic segments. As soon as the buds are formed the ventral primary rami from the spinal nerves penetrate into the mesenchyme. Initially each ventral ramus divides into dorsal and ventral branches, later these branches unite to form named peripheral nerves which supply extensor and flexor group of muscles respectively. Immediately after the above mentioned rearrangement of nerves, they enter the limb buds and establish an intimate contact with the differentiating mesodermal condensations and this early contact between the nerve and muscle cells is a essential prerequisite for their complete functional differentiation. [2]

Two principle theories have emerged concerning the directional growth of nerve fibersthe neurotropism or chemotropism hypothesis of Ramon et al [3] and the principle of contact guidance of Weiss.[4] The salient feature of chemotropism is that axonal growth cones act as sensors to concentration gradients of molecules in the environment and grow up the gradient towards the target [source]. There is no doubt, however that contact guidance mechanisms operate in parallel with neurotropism. Adhesion to the structures with which the growth cone contacts also plays a role. A group of cell surface receptors viz. neural cell adhesion molecule (N - CAM) and L1 and the cadherins act as transcription factors which recognize and bind to components of the extracellular matrix. Thus, both cell - cell and cell - matrix interactions may be involved in axonal path finding. Over or under expression of one or multiple transcription factors as mentioned above have been found to be responsible for the variations in the formation, relation and distribution of motor nerve fibers [5]. The variation noted in this present case can be attributed to misexpression of one or more transcription factors as mentioned above.

Similar type of right sided unilateral variation in the formation of median nerve by two lateral roots and one medial root was reported by Saeed and Rufai (2003) [6]and N.satyanarayan, C.K.Reddy(2010) [7]. A very rare variation in the formation of median nerve by four roots - three lateral roots and one medial root was also reported by N. Satyanarayan and Guha. $\mathrm{R}$ in 2008 [8]. Bilateral variations in the formation of median nerve was reported by N. Goyal, Harjeet, M Gupta in 2005 [9] Where in additional lateral roots co0ntributed to the formation of median nerve in an adult male cadaver. Anomalous left-sided formation of median nerve: by two medial and two lateral roots was reported by Aggarwal A. [10]

CONCLUSION: The knowledge of the formation, course and distribution with all the possible variations of median nerve is an essential pre-requisite for traumatologists, neurologists, surgeons performing shoulder arthroscopy by anterior gleno-humeral portal and shoulder reconstructive surgeries, neuro-surgeons performing neurotization [nerve repair, nerve transfer] of median nerve

ACKNOWLEDGEMENTS Thanks to George Williams (Librarian) and Mohammad Irfan Ali (2nd year MBBS student - Shadan Medical College, Hyd ( A.P) 


\section{REFERENCES:}

1. Williams PL, Bannister LH, Berry MM et al. Gray's Anatomy. In: Nervous System. $38^{\text {th }}$ ed. London Churchill Livingstone. 1999. 1270.

2. Saddler TW. Langman's Medical Embryology. In: Muscular system. $10^{\text {th }}$ ed. Philadelphia Lippincott Williams and Wilkins, 2006; 146-147.

3. Ramon y. Cajal S. Accion neurotropica de los epitelios. Algunos detalles sobre el mecanismo genetic de las ramificaciones nerviosas intraepiteliales sensitivas y sensoriales. Trab Lab Invest Biol 1919; 17: 65-8

4. Weiss P. Nerve patterns: the mechanics of nerve growth. Growth (supple 5) 1941;163203

5. Williams PL, Bannister LH, Berry MM et al. Grays's Anatomy. In: Embryology and development. 38 th ed. London Churchill Livingstone, 1999: 231 - 232.

6. Saeed and rufai, A.A Median nerve and musculocutaneous nerves: variant formation and distribution. Clinical Anatomy. 2003: 16: 453-7.

7. N. Satyanarayana. C. K Reddy, P. Sunitha, N. Jayasri, V. Nithin, G. Praveen, R. Guha, A.K. Datta, M.M shaik. Formation of median nerve by three roots: A case report. Journal of College of Medical Sciences - Nepal, 2010 Vol-6, No. 1, 47 - 50.

8. N. Satayanarayana and Guha. R formation of median nerve by four roots. Junior College of Medical Sciences 2008; vol. 5 no. 105-7.

9. N Goyal . Harjeet . M Gupta. Bilateral variant contributions in the formation of median nerve. Surg Radiol Anat (2005) 27: 562 - 565. DOI 10.1007/s00276-005-0023-6.

10. Aggarwal A, harjeet, K, Sahni D, Aggarwal A. bilateral multiple complex variations in the formation and branching pattern of brachial plexus, Surg Radiol Anat 2009 Apr 22.

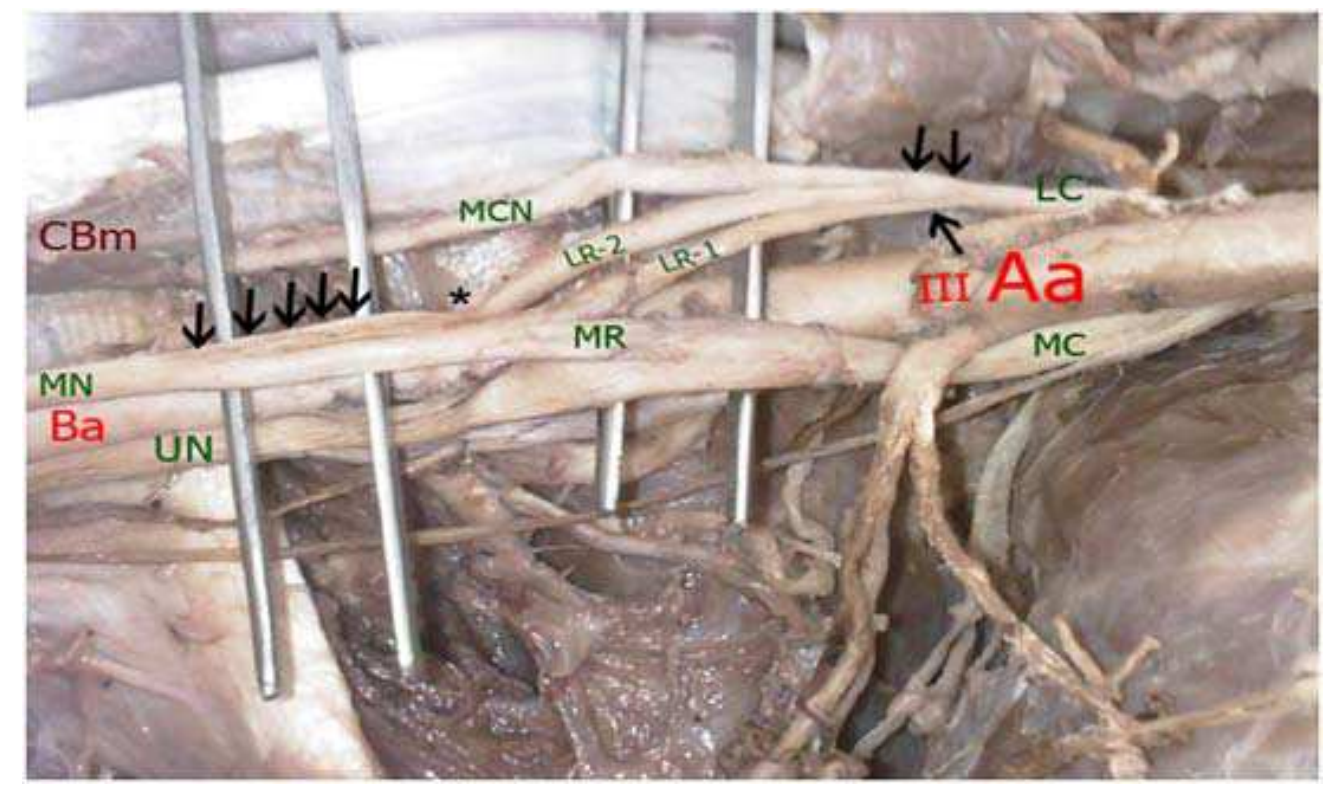

Figure - 1 Antero medial view of the brachial plexus in the right upper arm showing the variant $\mathrm{l}$ formation of median nerve by three roots. 


\section{CASE REPORT}

MR - Medial Root, LR - 1 - first lateral root, LR - 2 second Lateral Root, LC - Lateral Cord, Mc Medial Cord, III Aa - Third part of Axillary Artery, Ba - Brachial Artery, MN - Median Nerve, UN - Ulnar Nerve, CBm - Coraco -brachialis Muscle, MCN - Musculocutaneous Nerve,

Single Arrow - Showing the origin of Lateral root - 1 (LR - 1), Double Arrow showing the origin of Musculocutaneous Nerve and the lateral root - 2 (LR - 2) The multiple arrows show the course of lateral root -2 , lying antero - laterally on the median nerve remained distinct with its individual identity appreciable for a length of $3.5 \mathrm{~cm}$ before merging with the nerve

* The Star is indicating the kink / pinched appearance shown by the LR - 2, at the site of joining with the already formed median nerve. 